\title{
PENGARUH PEMBANGUNAN JALAN LINGKAR (JALAN SUDIRMAN - PROF. HAMKA) TERHADAP KINERJA JARINGAN JALAN DI KABUPATEN PASAMAN BARAT
}

\author{
Dewa Putu Wawan Darmadi ${ }^{1}$, I Made Arka Hermawan ${ }^{2 *}$, Ujang Cahyono ${ }^{3}$ \\ 1), 2), 3)PTDI-STTD \\ *Email: arkahermawan@ptdisttd.ac.id
}

\begin{abstract}
The construction of SUDIRMAN - PROF. HAMKA Ring Road in Pasaman Barat Regency aims to anticipate declining of road level of service and reduce traffic volume in the only one primary artery road acces to Simpang Empat City, the most vital economic and logistic area in Pasaman Barat Regency. These ring roads expected to reroute the passing through traffic in primary artery road Simpang Empat, to the new route through the new Sudirman - Prof. Hamka ring road. The method that used in evaluating the performance of the road network is by comparing the performance between two after-before condition, between no ring road were built or called do nothing condition and there is ring road built or called do something condition. Then, comparing and analyzing how far the ring road influencing the road network performance. In the planning year after the Sudirman - Prof. Hamka Ring Road built up, network performance in Pasaman Barat Regency increased when it compared without the construction of the Sudirman - Prof. Hamka Ring Road. In 2022, the value of v/c ratio decreasing from 0,92 to 0,45 while the the speed will increasing from $40 \mathrm{~km} / \mathrm{h}$ to $70 \mathrm{~km} / \mathrm{h}$. In 2027, the value of v/c ratio decreasing from 1,01 to 0,63 while the the speed will increasing from $28 \mathrm{~km} / \mathrm{h}$ to $60 \mathrm{~km} / \mathrm{h}$. The construction of Sudirman - Prof. Hamka Ring Road in 2022 or even in 2027, will make the network performance in Pasaman Barat Regency improved.
\end{abstract}

Keywords: Road Network Performance, Road Perfomance, Ring Road.

\begin{abstract}
ABSTRAK
Pembangunan Jalan Lingkar (Jalan Sudirman - Prof. Hamka) di Kabupaten Pasaman Barat bertujuan untuk mengantisipasi penurunan tingkat pelayanan dan mengurangi volume lalu lintas di ruas jalan arteri primer yang menjadi satu-satunya akses masuk menuju Seimpang Empat, yang juga merupakan jalur akses vital bagi perekonomian dan rantai pasok. Dengan adanya jalan lingkar ini diharapkan perjalanan menerus yang melewati Kabupaten Pasaman Barat yang saat ini melewati jalan arteri primer di perkotaan beralih ke jalan Lingkar (Jalan Sudirman - Prof. Hamka). Metode yang digunakan dalam mengevaluasi kinerja jaringan jalan yaitu dengan membandingkan kinerja jalan pada saat sebelum dilakukan pembangunan jalan lingkar (do nothing) dengan kinerja jalan pada saat setelah dilakukan pembangunan jalan lingkar (do something), setelah dilakukan perbandingan maka akan dianalisis sejauh mana pengaruh pembangunan jalan lingkar (Jalan Sudirman - Prof. Hamka) terhadap jaringan jalan di wilayah tersebut baik eksisting maupun di masa mendatang. Pada tahun rencana setelah jalan lingkar (Jalan Sudirman - Prof. Hamka) dibangun kinerja jaringan di Kabupaten Pasaman Barat meningkat menjadi $51 \mathrm{~km} / \mathrm{jam}$ dari sebelumnya $47 \mathrm{~km} / \mathrm{jam}$ pada tahun 2022. Pada tahun 2027 , kecepatan meningkat dari $39 \mathrm{~km} / \mathrm{jam}$ menjadi $46 \mathrm{~km} / \mathrm{jam}$. Kinerja ruas Jalan Sudirman juga meningkat dari v/c rasio 0,92 menjadi 0,45 serta kecepatan dari $40 \mathrm{~km} / \mathrm{jam}$ menjadi 70 $\mathrm{km} / \mathrm{jam}$ pada tahun 2022. Tahun 2027, Jalan Sudirman mengalami peningkatan dari v/c rasio 1,01 menjadi 0,63 dan kecepatan dari $38 \mathrm{~km} / \mathrm{jam}$ menjadi $60 \mathrm{~km} / \mathrm{jam}$. Adanya pembangunan jalan lingkar baik pada tahun 2022 maupun 2027 akan meningkatkan kinerja jaringan dan kinerja ruas di wilayah studi.
\end{abstract}

Kata Kunci: Kinerja Jaringan Jalan, Kinerja Ruas Lintas, Jalan Lingkar. 


\section{PENDAHULUAN}

Kabupaten Pasaman Barat merupakan kabupaten yang baru diresmikan pada tahun 2004 sehingga pembangunan infrastruktur yang berfungsi menunjang pertumbuhan ekonomi belum terlaksana secara optimal. Salah satu bentuk infrastruktur penting guna menunjang perekonomian adalah jalan. Kabupaten Pasaman Barat memiliki 3 ruas jalan jalan arteri, 4 ruas jalan kolektor dan 163 jalan lokal. Salah satu jalan arteri primer yang menjadi akses satu-satunya dari luar Kabupaten Pasaman Barat menuju Simpang Empat adalah Jalan Sudirman.

Selain itu sebagai akses menuju Simpang Empat, jalan tersebut juga menjadi jalur pengiriman barang seperti hasil buah dari perkebunan kelapa sawit dan olahan minyak kelapa sawit. Akibat jalur perjalanan yang hanya bertumpu pada satu ruas maka Jalan Jend. Sudirman memiliki nilai vc rasio 0,6 dan kecepatan tempuh $45 \mathrm{~km} / \mathrm{jam}$. Menurut Peraturan Menteri Perhubungan Nomor 96 Tahun 2015 tentang "Pedoman Pelaksanaan Kegiatan Manajemen Dan Rekayasa Lalu Lintas" menyatakan bahwa ruas tersebut termasuk dalam tingkat pelayanan E. Karakteristik tingkat pelayanan E adalah kondisi arus yang tidak stabil dan kepadatan tinggi disebabkan oleh hambatan internal. Untuk mengatasi adanya permasalahan yang berkaitan dengan lalu lintas pada tahun eksisting serta penurunan tingkat pelayanan dalam 5 sampai 10 tahun kedepan maka perlu diselenggarakannya manajemen dan rekayasa lalu lintas dalam bentuk rencana pembangunan jalan lingkar.

Adanya usulan rencana pembangunan jalan lingkar di Kabupaten Pasaman Barat menimbulkan adanya kajian yang memberikan gambaran kinerja lalu lintas pada jaringan jalan di Kabupaten Pasaman yang mengalami masalah sebelum dan setelah pembangunan jalan. Dengan demikian, kajian ini diharapkan dapat dijadikan bahan untuk pengambilan kebijakan yang berkaitan dengan kinerja jaringan jalan dan lalu lintas oleh Pemerintah Kabupaten Pasaman Barat. Melalui penjelasan singkat di atas, maka peneliti berkeinginan untuk meneliti mengenai pengaruh dari pembangunan jalan lingkar kepada kinerja jaringan di Kabupaten Pasaman Barat.

\section{KAJIAN LITERATUR \\ Permodelan Transportasi}

Model transportasi adalah simplikasi dan simulasi untuk mempresentasikan keadaan yang sesungguhnya dan kemungkinan yang akan terjadi terhadap sistem transportasi pada masa yang akan datang. Tahapan-tahapan dala perencanaan transportasi dapat dilihat pada bagan alir perencanaan transportasi berikut ini:

a) Bangkitan Perjalanan (Trip Generation)

Bangkitan perjalanan adalah banyaknya jumlah perjalanan/pergerakan/lalu-lintas yang dibangkitkan oleh suatu zona (kawasan) yang ada di Kabupaten Pasaman Barat per satuan waktu, yang mana perjalanan dilakukan oleh setiap anggota keluarga yang ada pada setiap zona internal. Dimana data-data diperoleh dari survai wawancara rumah tangga dan survai wawancara pinggir jalan.

b) Distribusi Perjalanan (Trip Distribution)

Distribusi perjalanan merupakan proses yang berhubungan dengan jumlah asal dan tujuan perjalanan tiap zona dalam daerah studi. Pada tahap ini mempertimbangkan penetapan hubungan interaksi antara sejumlah zona berdasarkan bangkitan dan tarikan perjalanan yang telah dilakukan pada tahap sebelumnya.

c) Pemilihan Moda (Moda Split) 
Pelaku perjalanan dapat memilih diantara pilihan penggunaan moda, seperti kendaraan umum, kendaraan pribadi, sepeda motor, dan kendaraan tidak bermotor. John Black (1981) menyatakan bahwa dalam analisis pemilihan moda dapat dilakukan pada tahap yang berbeda-beda dalam proses permodelan.

d) Pembebanan Perjalanan (Trip Assignment)

Ofyar Z. Tamin (1997) menyatakan bahwa tahap pembebanan perjalanan memerlukan data masukan berupa matrik asal dan tujuan perjalanan, kapasitas jalan, dan karakteristik jaringan seperti jarak dan waktu tempuh antar zona. Menentukan jumlah perjalanan yang membebani selurus ruas jalan yang ada, dari satuan perjalanan orang per hari dikonversikan ke satuan kendaraan per hari. Matrik yang dibebankan berbentuk perjalanan perjam atau smp (satuan mobil penumpang) perjam. Bentuk keluaran dari proses pembebanan ini berupa arus kendaraan tiap ruas atau biaya dan waktu tempuh perjalanan.

e) Validasi Model

Validasi model merupakan suatu proses untuk menguji hasil permodelan transportasi sebelum model tersebut digunakan lebih lanjut.

\section{Metode Analisa Unjuk Kerja Lalu Lintas}

a) Kapasitas Jalan

Kapasitas jalan didefinisikan sebagai arus maksimum melalui suatu titik di jalan yang dapat dipertahankan per satuan jam pada kondisi tertentu. Untuk jalan dualajur dua-arah, kapasitas ditentukan untuk arus dua arah (kombinasi dua arah), tetapi untuk jalan dengan banyak lajur, arus dipisahkan per arah dan kapasitas ditentukan per lajur. Dalam MKJI, kapasitas ruas jalan dibedakan untuk jalan perkotaan, jalan luar kota, dan jalan bebas hambatan.

b) Kecepatan

Dalam buku Manual Kapasitas Jalan Indonesia (1997), kecepatan didefinisikan dalam beberapa hal antara lain:

Kecepatan perjalanan/kecepatan tempuh adalah kecepatan kendaraan (biasanya $\mathrm{Km} / \mathrm{jam}$ atau $\mathrm{m} / \mathrm{s}$ ). Selain itu, kecepatan tempuh didefinisikan sebagai kecepatan rata-rata arus lalu lintas dihitung dari panjang jalan dibagi waktu tempuh rata-rata kendaraan yang melalui ruas jalan. Manual Kapasitas Jalan Indonesia (1997), menggunakan kecepatan tempuh sebagai ukuran utama kinerja segmen jalan, karena ini mudah dimengerti dan diukur dan merupakan masukan yang penting bagi biaya pemakai jalan dalam analisa ekonomi.

c) Kepadatan Ruas

Kepadatan yaitu didefinisikan sebagai konsentrasi dari kendaraan di jalan. Kepadatan biasanya dinyatakan dalam satuan kendaraan per kilometer. Kepadatan dapat dinyatakan dengan perbandingan antara aliran lalu lintas dengan kecepatan.

d) Tingkat Pelayanan

Menurut Khisty \& Lall (2003) Tingkat pelayanan (Level Of Service, LOS) adalah suatu ukuran kualitatif yang menjelaskan kondisi-kondisi operasional di dalam suatu aliran lalu lintas dan persepsi dari pengemudi dan/atau penumpang terhadap kondisi-kondisi tertentu. Faktor-faktor seperti kecepatan dan waktu tempuh, kebebasan bermanuver, perhentian lalu lintas, dan kemudahan serta kenyamanan adalah kondisi-kondisi yang mempengaruhi LOS. 


\section{METODE}

Penelitian dilaksanakan melalui berbagai tahapan berupa identifikasi masalah, pengumpulan data, pengolahan data dan hasil kesimpulan. Data yang digunakan berupa data sekunder dan data primer melalui pendekatan literaur yang berhubungan dengan penelitian. Analisis kemudian akan dilaksanakan kepada pembangunan jalan lingkar serta akibatnya kepada kinerja jaringan jalan.

\section{PEMBAHASAN}

\section{Strategi Perencanaan Penanganan}

Dalam menangani permasalahan lalu lintas yang ditimbulkan oleh kenaikan volume lalu lintas setiap tahunnya pada ruas jalan eksisting maka Pemerintah Kabupaten Pasaman Barat yang bekerja sama dengan instansi terkait seperti Dinas Pekerjaan Umum dan Perumahan Rakyat. Dinas Perhubungan Kabupaten Pasaman Barat memiliki rencana mengusulkan dan membandingkan dengan usulan penanganan yaitu 'Pembangunan Jalan Lingkar'.

Letak pembangunan jalan lingkar tersebut direncanakan dibangun melalui daerah yang jauh dari pemukiman. Sehingga tidak menimbulkan adanya permasalahan terkait sengketa lahan. Lahan yang digunakan merupakan lahan hutan yang dikelola oleh Pemerintah Kabupaten Pasaman Barat. Kontur di wilayah studi cenderung datar dan tidak terlalu banyak terdapat daerah perbukitan dan pegunungan. Sehingga dana untuk membangun jalan lingkar dapat difedektifkan. Selain mengenai tata guna lahan dan kontur daerah d wilayah studi, pembangunan jalan lingkar mengambil jalan sebelah selatan dari (pusat kota) Simpang Ampek dikarenakan jumlah dan simpang yang lebih sedikit daripada usulan pembangunan jalan lingkar pada sisi barat.

Perbandingan kinerja lalu lintas akan dilakukan dalam keadaan tanpa (do nothing) dan dibangunnya jalan lingkar (do something) pada tahun 2022 dan 2027. Dengan adanya jalan lingkar tersebut. maka akan terbangun link dan node yang baru yang akan memberikan dampak pada kinerja jaringan di Kabupaten Pasaman Barat. Berikut adalah peta lokasi rencana usulan pembangunan jalan lingkar.

a) Perencanaan Penanganan dengan Pembangunan Jalan Lingkar Tahun 2022 Pembangunan Jalan Lingkar (Ring Road) Kabupaten Pasaman Barat. Adapun kinerja ruas jalan tahun 2022 pada saat set elah dibangun jalan lingkar dapat dilihat pada tabel 1 dibawah ini:

Tabel 1. Unjuk Kinerja Ruas Jalan Tahun 2022 (do something)

\begin{tabular}{|c|c|c|c|}
\hline No. & Nama Jalan & $\begin{array}{c}\text { Kecepatan } \\
\text { Ruas (km/jam) }\end{array}$ & V/C rasio \\
\hline 1 & JL. JEND. SUDIRMAN (link 1) & 70 & 0,45 \\
\hline 2 & JL. JEND. SUDIRMAN (link 2) & 63 & 0,57 \\
\hline 3 & JL. JEND. SUDIRMAN (link 3) & 65 & 0,48 \\
\hline 4 & JL. JEND. SUDIRMAN (link 4) & 66 & 0,49 \\
\hline 5 & JL. JEND. SUDIRMAN (link 5) & 65 & 0,55 \\
\hline 6 & JL. PROF. HAMKA (link 1) & 62 & 0,35 \\
\hline 7 & JL. PROF. HAMKA (link 2) & 62 & 0,35 \\
\hline 8 & JL. PROF. HAMKA (link 3) & 61 & 0,60 \\
\hline 9 & JL. PROF. HAMKA (link 4) & 55 & 0,14 \\
\hline 10 & JL. TUANGKU SASAK (link 1) & 0,30 \\
\hline
\end{tabular}




\begin{tabular}{|c|c|c|c|}
\hline 11 & JL. TUANGKU SASAK (link 2) & 46 & 0,55 \\
\hline 12 & JL. TUANGKU SASAK (link 3) & 66 & 0,62 \\
\hline 13 & JL. TUANGKU SASAK (link 4) & 51 & 0,43 \\
\hline 14 & JL. TUANGKU SASAK (link 5) & 51 & 0,43 \\
\hline 15 & JL. TUANGKU IMAM BONJOL (link 1) & 46 & 0,56 \\
\hline 16 & JL. TUANGKU IMAM BONJOL (link 2) & 42 & 0,64 \\
\hline 17 & JL. TUANGKU IMAM BONJOL (link 3) & 60 & 0,71 \\
\hline 18 & JL. TUANGKU IMAM BONJOL (link 4) & 57 & 0,83 \\
\hline 19 & JL. TUANGKU IMAM BONJOL (link 5) & 57 & 0,80 \\
\hline 20 & JL. TUANGKU IMAM BONJOL (link 6) & 57 & 0,44 \\
\hline 21 & JL. SOEKARNO HATTA (link 1) & 52 & 0,31 \\
\hline 22 & JL. SOEKARNO HATTA (link 2) & 42 & 0,34 \\
\hline 23 & JL. SOEKARNO HATTA (link 3) & 48 & 0,34 \\
\hline 24 & JL. SOEKARNO HATTA (link 4) & 59 & 0,30 \\
\hline 25 & JL. SOEKARNO HATTA (link 5) & 60 & 0,30 \\
\hline 26 & JL. SOEKARNO HATTA (link 6) & 57 & 0,32 \\
\hline 27 & JL. FLAMBOYAN & 48 & 0,43 \\
\hline 28 & JL. SIMPANG 3 OPHIR & 48 & 0,32 \\
\hline 29 & JL. JEND. MAYOR ZAM ZAM & 48 & 0,43 \\
\hline 30 & JL. CINDUA MATO & 48 & 0,32 \\
\hline 31 & JL. M. NATSIR (link 1) & 50 & 0,09 \\
\hline 32 & JL. M. NATSIR (link 2) & 50 & 0,08 \\
\hline 33 & JL. BUYA LUBUAK LANDUO & 51 & 0,10 \\
\hline 34 & JL. BANDARA PUSAKO & 54 & 0,15 \\
\hline 35 & JL. JERUK & 54 & 0,28 \\
\hline 36 & JL. KAPA SIMP. 4 & 52 & 0,31 \\
\hline 37 & JL. PERTANIAN & 34 & 0,24 \\
\hline 38 & JL. SIMPANG TANJUNG PANGKAL & 46 & 0,30 \\
\hline 39 & JL. TARANDAM & 45 & 0,24 \\
\hline
\end{tabular}

Sedangkan unjuk kerja jaringan jalan pada tahun 2022 setelah dilakukan pembangunan Jalan Lingkar adalah sebagai berikut:

1) Kecepatan Rata - Rata

2) Total Panjang Perjalanan

3) Waktu tempuh

$$
\begin{aligned}
& =51,11 \mathrm{~km} / \mathrm{jam} \\
& =12.982,34 \mathrm{~km} \\
& =253,91 \mathrm{jam}
\end{aligned}
$$

Jika dibandingkan dengan kecepatan rata-rata sebelum dibangunnya jalan lingkar (do nothing). kecepatan meningkat dari $47 \mathrm{~km} / \mathrm{jam}$ menjadi 51,11 km/jam. Dapat diambil kesimpulan. pembangunan jalan lingkar tersebut dapat meningkatkan kinerja ruas dan jaringan di Kabupaten Pasaman Barat.

b) Perencanaan Penanganan dengan Pembangunan Jalan Lingkar Tahun 2027 Pembangunan Jalan Lingkar (Ring Road) Kabupaten Pasaman Barat. Adapun kinerja ruas jalan tahun 2027 pada saat setelah dibangun jalan baru dapat dilihat pada tabel 2 dibawah ini:

Tabel 2. Unjuk Kinerja Ruas Jalan Tahun 2027 (do something) 


\begin{tabular}{|c|c|c|c|}
\hline No & Nama Jalan & $\begin{array}{c}\text { Kecepatan Ruas } \\
(\mathbf{k m} / \mathbf{j a m})\end{array}$ & V/C Rasio \\
\hline 1 & JL. JEND. SUDIRMAN (link 1) & 60 & 0,63 \\
\hline 2 & JL. JEND. SUDIRMAN (link 2) & 53 & 0,57 \\
\hline 3 & JL. JEND. SUDIRMAN (link 3) & 55 & 0,53 \\
\hline 4 & JL. JEND. SUDIRMAN (link 4) & 54 & 0,76 \\
\hline 5 & JL. JEND. SUDIRMAN (link 5) & 54 & 0,76 \\
\hline 6 & JL. PROF. HAMKA (link 1) & 65 & 0,27 \\
\hline 7 & JL. PROF. HAMKA (link 2) & 64 & 0,30 \\
\hline 8 & JL. PROF. HAMKA (link 3) & 49 & 0,65 \\
\hline 9 & JL. PROF. HAMKA (link 4) & 67 & 0,22 \\
\hline 10 & JL. TUANGKU SASAK (link 1) & 50 & 0,63 \\
\hline 11 & JL. TUANGKU SASAK (link 2) & 43 & 0,63 \\
\hline 12 & JL. TUANGKU SASAK (link 3) & 46 & 0,74 \\
\hline 13 & JL. TUANGKU SASAK (link 4) & 49 & 0,79 \\
\hline 14 & JL. TUANGKU SASAK (link 5) & 50 & 0,59 \\
\hline 15 & JL. TUANGKU IMAM BONJOL (link 1) & 56 & 0,82 \\
\hline 16 & JL. TUANGKU IMAM BONJOL (link 2) & 36 & 0,81 \\
\hline 17 & JL. TUANGKU IMAM BONJOL (link 3) & 39 & 0,72 \\
\hline 18 & JL. TUANGKU IMAM BONJOL (link 4) & 35 & 0,75 \\
\hline 19 & JL. TUANGKU IMAM BONJOL (link 5) & 37 & 0,79 \\
\hline 20 & JL. TUANGKU IMAM BONJOL (link 6) & 38 & 0,77 \\
\hline 21 & JL. SOEKARNO HATTA (link 1) & 46 & 0,40 \\
\hline 22 & JL. SOEKARNO HATTA (link 2) & 46 & 0,45 \\
\hline 23 & JL. SOEKARNO HATTA (link 3) & 53 & 0,43 \\
\hline 24 & JL. SOEKARNO HATTA (link 4) & 52 & 0,42 \\
\hline 25 & JL. SOEKARNO HATTA (link 5) & 53 & 0,39 \\
\hline 26 & JL. SOEKARNO HATTA (link 6) & 54 & 0,42 \\
\hline 27 & JL. FLAMBOYAN & 34 & 0,41 \\
\hline 28 & JL. SIMPANG 3 OPHIR & 37 & 0,29 \\
\hline 29 & JL. JEND. MAYOR ZAM ZAM & 34 & 0,41 \\
\hline 30 & JL. CINDUA MATO & 37 & 0,29 \\
\hline 31 & JL. M. NATSIR (link 1) & 37 & 0,28 \\
\hline 32 & JL. M. NATSIR (link 2) & 40 & 0,09 \\
\hline 33 & JL. BUYA LUBUAK LANDUO & 38 & 0,24 \\
\hline 34 & JL. BANDARA PUSAKO & 37 & 0,27 \\
\hline 35 & JL. JERUK & 34 & 0,43 \\
\hline 36 & JL. KAPA SIMP. 4 & 36 & 0,33 \\
\hline 37 & JL. PERTANIAN & 38 & 0,21 \\
\hline 38 & JL. SIMPANG TANJUNG PANGKAL & 36 & 0,33 \\
\hline 39 & JL. TARANDAM & 38 & 0,21 \\
\hline
\end{tabular}


Sedangkan unjuk kerja jaringan jalan pada tahun 2027 setelah dilakukan pembangunan Jalan Lingkar adalah sebagai berikut:
1) Kecepatan Rata - Rata
$=46 \mathrm{~km} / \mathrm{jam}$
2) Total Panjang Perjalanan
$=15.728,5 \mathrm{~km}$
3) Waktu tempuh
$=346.8 \mathrm{jam}$

Jika dibandingkan dengan kecepatan rata-rata sebelum dibangunnya jalan lingkar (do nothing). kecepatan meningkat dari 39,68 km/jam menjadi $46 \mathrm{~km} / \mathrm{jam}$. Dapat diambil kesimpulan. pembangunan jalan lingkar tersebut dapat meningkatkan kinerja ruas jaringan di Kabupaten Pasaman Barat.

\section{Perbandingan Kinerja Ruas Jalan dan Jaringan Sebelum Penanganan (Do Nothing) dan Setelah Penanganan (Do Something)}

Berdasarkan data-data hasil pembebanan usulan dibangunnya beberapa usulan dengan menggunakan software transportasi yaitu VISUM versi 17 maka dapat dilakukan perbandingan kinerja jaringan jalan pada tahun 2022 dan 2027 (Do Nothing). 2022 dan 2027 (Do Something) serta tahun 2022 dan 2027 (Do Something). Perbandingan kinerja ini dimaksudkan untuk mengetahui bagaimana kinerja lalu lintas serta kinerja jaringan di wilayah studi baik dengan adanya penanganan ataupun tanpa adanya penanganan.

Dari data perbandingan V/C ratio dan kecepatan didapatkan bahwa setelah dibangunnya jalan lingkar maka dapat meningkatkan kinerja ruas jalan yang ada. hal ini ditandai dengan turunnya nilai $\mathrm{V} / \mathrm{C}$ ratio dan meningkatnya kecepatan pada beberapa ruas jalan. Oleh karena itu dapat disimpulkan bahwa usulan pembangunan jalan lingkar tersebut dapat meningkatkan kinerja ruas pada 5 sampai 10 tahun mendatang.

Berikut perbandingan kinerja jaringan jalan sebelum dan setelah dibangun jalan lingkar dapat dilihat pada tabel 3 di bawah ini:

Tabel 3. Perbandingan Unjuk Kerja Jaringan Kondisi Eksisting. Do Nothing dan Do Something Tahun 2022 dan tahun 2027

\begin{tabular}{|c|c|c|c|c|c|c|c|c|c|}
\hline \multirow{2}{*}{ SKENARIO } & \multicolumn{3}{|c|}{$\begin{array}{c}\text { Kecepatan Rata-Rata } \\
\mathbf{( k m / j a m )}\end{array}$} & \multicolumn{3}{c|}{ Jarak Perjalanan Total (km) } & \multicolumn{3}{c|}{ Waktu Tempuh (menit) } \\
\cline { 2 - 11 } & $\mathbf{2 0 1 7}$ & $\mathbf{2 0 2 2}$ & $\mathbf{2 0 2 7}$ & $\mathbf{2 0 1 7}$ & $\mathbf{2 0 2 2}$ & $\mathbf{2 0 2 7}$ & $\mathbf{2 0 1 7}$ & $\mathbf{2 0 2 2}$ & $\mathbf{2 0 2 7}$ \\
\hline $\begin{array}{c}\text { Tanpa } \\
\text { Penanganan }\end{array}$ & 49 & 47 & 39 & $12.276,4$ & $16.568,8$ & $20.000,7$ & 233,8 & 353,2 & 503,8 \\
\hline $\begin{array}{c}\text { Usulan Jalan } \\
\text { Lingkar }\end{array}$ & - & 51 & 46 & - & $12.982,3$ & $15.728,5$ & - & 253,9 & 346,7 \\
\hline
\end{tabular}

Dari data perbandingan unjuk kerja jaringan jalan tahun 2022 antara kondisi eksisting (do nothing) dengan kondisi usulan (do something) dapat diketahui bahwa unjuk kerja jaringan jalan pada tahun 2022 dengan usulan jalan skenario dibangunnya jalan lingkar mengalami peningkatan. Hal yang sama terjadi pada tahun 2027 Pembangunan jalan baru pada tahun 2027 dapat meningkat kinerja lalu lintas dan kinerja jaringan.

\section{KESIMPULAN}

Berdasarkan hasil analisis yang telah dijelaskan pada bab sebelumnya maka dapat diambil kesimpulan bahwa pembebanan lalu lintas tahun 2022 dan 2027 tanpa adanya penanganan mengakibatkan kinerja lalu lintas menjadi menurun, Salah satu ruas jalan dengan kinerja terburuk adalah Jalan Jendral Sudirman (link 1) dengan V/C rasio 0,92 dan kecepatan $38 \mathrm{~km} / \mathrm{jam}$ pada tahun 2022 dan V/C rasio 1,01 dan kecepatan $28 \mathrm{~km} / \mathrm{jam}$ pada tahun 2027. 
Setelah adanya usulan pembangunan jalan lingkar di Kabupaten Pasaman Barat, kinerja lalu lintas menjadi meningkat. Jika ditinjau dari Jalan Jendral Sudirman (link 1), dibandingkan dengan tahun 2022 dan 2027 ketika tanpa ada penanganan, V/C rasio menurun menjadi 0,45 dan kecepatan meningkat menjadi $70 \mathrm{~km} / \mathrm{jam}$ pada tahun 2022 . Selain itu, pada tahun 2027 ketika dilakukan penanganan, nilai V/C rasio pada jalan Sudirman (link1) adalah 0,63 dengan kecepatan 60. Jadi, dapat diambil kesimpulan bahwa adanya usulan pembangunan jalan lingkar dapat meningkatkan kinerja ruas jalan di Kabupaten Pasaman barat pada 5 sampai 10 tahun kedepan.

Kemudian, pembangunan jalan lingkar juga mempengaruhi kinerja jaringan di Kabupaten Pasaman Barat. Sebelum adanya jalan lingkar kecepatan rata-rata pada tahun 2022 (do nothing) adalah $46 \mathrm{~km} / \mathrm{jam}$ dan pada tahun 2027 (do nothing) adalah $39 \mathrm{~km} / \mathrm{jam}$ sedangkan setelah dibangunnya jalan lingkar kecepatan rata-rata pada tahun 2022 (do something) meningkat menjadi $49 \mathrm{~km} / \mathrm{jam}$ dan pada tahun 2027 (do something) menjadi $46 \mathrm{Km} / \mathrm{jam}$.

\section{DAFTAR PUSTAKA}

1. Arif, Ferdi. 2014. Optimalisasi Jalan Lingkar Barat dan Pengaruhnya Terhadap Tata Guna Lahan di Kabupaten Tulungagung. Bekasi: Sekolah Tinggi Transportasi Darat.

2. Kristanto, Jati. (2014). Analisis Kinerja Lalu Lintas dan Operasional Jalan Lingkar Selatan Juwana di Kabupaten Pati. Bekasi: Sekolah Tinggi Transportasi Darat.

3. Morlok, Edward K., 1978, Pengantar Teknik dan Perencanaan Transportasi, Erlangga, Jakarta.

4. Munawar, Ahmad. 1997. Manajemen Transportasi Perkotaan Yang Berwawasan Lingkungan, Manyarakat Transportasi Indonesia. Jakarta.

5. Republik Indonesia. 1997. Manual Kapasitas Jalan Indonesia. Swearoad \& Bina Karya.

6. Republik Indonesia. 2004. Undang - undang Republik Indonesia Nomor 38 Tahun 2004 tentang Jalan. Jakarta.

7. Republik Indonesia. 2006. Modul Rekayasa Lalu Lintas. Bekasi: Sekolah Tinggi Transportasi Darat.

8. Republik Indonesia. 2009. Undang-Undang Nomor 22 Tahun 2009 tentang Lalu Lintas dan Angkutan Jalan. Jakarta: Departemen Perhubungan.

9. Republik Indonesia. 2015. Peraturan Menteri Perhubungan Nomor 96 Tahun 2015 tentang Panduan Manajemen dan Rekayasa Lalu Lintas di Jalan, Kementrian Perhubungan. Jakarta.

10. Republik Indonesia. 2017. Laporan Umum Lalau Lintas Dan Angkutan Jalan Kabupaten Pasaman Barat Dan Identifikasi Permasalahannya. Bekasi: Sekolah Tinggi Transportasi Darat.

11. Satya, Sekar. 2011. Analisis Dampak Pembangunan Jalan Lingkar TErhadap Pola Pergerakan Lalu Lintas Di Kota Tarakan. Bekasi: Sekolah Tinggi Transportasi Darat.

12. Tamin, Ofyar Z. 2008. Perencanaan, Permodelan dan Rekayasa Transportasi. Bekasi: ITB.

13. Trilaksana, Adrian. 2006. Evaluasi Kinerja Jaringan Jalan Terhadap Adanya Pengembangan Jalan Lingkar Di Kota Wonogiri. Bekasi: Sekolah Tinggi Transportasi Darat, Bekasi. 
14. Virgiawan, Dicky. 2013. Peningkatan Pemanfaatan Jalan Lingkar Selatan Di Kabupaten Wonosobo. Bekasi: Sekolah Tinggi Transportasi Darat. 